\title{
Analysis of Harmonic Distortion in Building Electrical Installation with Computer Devices
}

\author{
João Pedro Trovão ${ }^{1}$, Paulo Pereirinha ${ }^{1}$, Humberto Jorge ${ }^{2}$ \\ ${ }^{1}$ Instituto Superior de Engenharia de Coimbra \\ Departamento Engenharia Electrotécnica \\ Rua Pedro Nunes, Quinta da Nora - P-3031-199 Coimbra (Portugal) \\ phone:+351 239790 200, fax:+351 239790 321, e-mail: \{jtrovao, ppereiri\}@isec.pt \\ ${ }^{2}$ Dep. de Eng. Electrotécnica e de Computadores \\ Faculdade de Ciências e Tecnologia - Universidade de Coimbra \\ Pólo II, Pinhal de Marrocos - P-3030-290 Coimbra (Portugal) \\ phone:+351 239796 200, fax:+ 351239796 247, e-mail: hjorge@deec.uc.pt
}

\begin{abstract}
This paper presents an analysis of the electrical installation in a educational facility building allowing the knowledge of its power supply quality. The work is based on data supply waveforms and PQ indexes, acquired by recent power analyser, allowing to study the voltage and current waveform distortion of this specific building, where the main load are computer devices. A set of methods and techniques to attenuate the harmonics amplitude in this type of installation is presented and discussed. It is proposed a solution for this case study, function of the total load, installation feeding and of the level of authorized distortion for the international standards. This study can provide some help in the future dimensioning and project of the electrical installation for this type of building, from the point of view of the distortion and the best localization of the problematic loads.
\end{abstract}

Key words: Harmonic Distortion Propagation, Power Quality, Building Installation, Computer Devices Power Quality.

\section{Introduction}

In the last years, nonlinear loads have been growing up in building equipments, namely with the proliferation of computer devices, printers, fans, Heating, Ventilating, and Air-Conditioning and Refrigeration (HVAC) systems, Uninterrupted Power Supply (UPS), and lifts. In its great majority, the loads considered as nonlinear are power electronic converters that allow adapting the source (feeding network, batteries, device sources, etc.) to the load requirements [1]. Today, these converters are used in an increasing number of the industrial or domestic equipments, namely, computers and its peripherals supplies, speed and position control of electric motors, luminous intensity regulation of halogen light bulbs, and power regulation of resistance ovens or of induction heating applications [1-2]. However, the use of those devices in electrical installations contributes to the deterioration of the Power Quality (PQ), namely in the current and voltage waveform of the distribution network. The absorption of non-sinusoidal currents, by elements of these systems, leads to harmonic currents circulation that, through the network impedance, results in supply voltage deformation.

These converters are then harmonic disturbances sources that can, in certain cases, aggravate or cause misfunction of sensible equipment, present in their neighbourhood. The misfunction or the stopping of priority devices, such as computers, illumination and security systems, can put the people's security at risk (hospitals, airport track delimitations, public places, tall buildings, etc.). Other consequences of harmonic disturbances, that are not easily quantified and usually are not imputed to this problematic, are, for example, the costs associated with the equipments life-time reduction, extra maintenance and productivity losses [2].

It is then convenient to take some precautions, reducing the levels of generated disturbances and to immunize the sensible equipment, in order to assure the reliability of the electric installations. To accomplish these objectives, it is very important to measure and analyse the harmonics distortion, study its impacts and propose corrective actions [3-5].

In this work, the origins and the possible consequences of the harmonics disturbances in the computer equipments and in the building distribution networks are studied. Also, there are presented and argued the main correction strategies in a building electric installation, in which the main loads are the computer devices. The case of the filtering (active or passive) of the disturbances and the conception of less disturbing equipment is considered. For this, the paper is organized as follows. In the introduction, a brief explanation of the problem, the purpose and the contribution of the work, are presented. Next, there are presented the basic concepts of the harmonic phenomena studied in this work. Then it describes the main kinds of harmonic corrections. Following, are shown sone results relative to a particular audit of a facility building with the 
application of the main standards, and some corrective measures are proposed. Finally, the main conclusions of this study are exposed.

\section{Harmonic Phenomena Basic Concepts}

Several concepts used in this study are presented in this section. The harmonic distortion is a pollution form of the electric network susceptive of being problematic if the sum of harmonics currents is bigger than some boundary-values. In Fig. 1, it can be seen as harmonics currents $\left(i_{h}\right)$ of the absorbed current $i_{c}$ by computer(s) device(s) will affect the voltage $\mathrm{u}(\mathrm{t})$ at the point of common coupling (PCC).

The quantitative indicators used to examine the waveform quality are the amplitude values of the trigonometric Fourier series decomposition, i.e., the harmonic values $\left(X_{k}\right)$ of the $k$ order, given by,

$$
\begin{aligned}
& X_{k}=\sqrt{a_{k}^{2}+b_{k}^{2}} \\
& a_{k}=\frac{2}{T} \int_{0}^{T} x(t) \cdot \cos k \omega t d t, \\
& b_{k}=\frac{2}{T} \int_{0}^{T} x(t) \cdot \sin k \omega t d t
\end{aligned}
$$

with $k=0,1,2 \ldots, \omega=2 \pi f$ and $f$ the system frequency. $X_{1}$ is the fundamental value.

The way as the current harmonics overlap (overlapping method) to the fundamental of the absorbed current is presented in Fig. 2, where it is only analyzed the overlapping of the $5 .^{\text {th }}$ and $7 .^{\text {th }}$ harmonics to the fundamental.

It is common to characterize the level of the harmonic distortion in a electrical network system through the Total Harmonic Distortion (THD), that quantifies the effective value of the harmonic distortion, and, according to North American IEEE $^{1}$ Standard [4], it is expressed by (5):

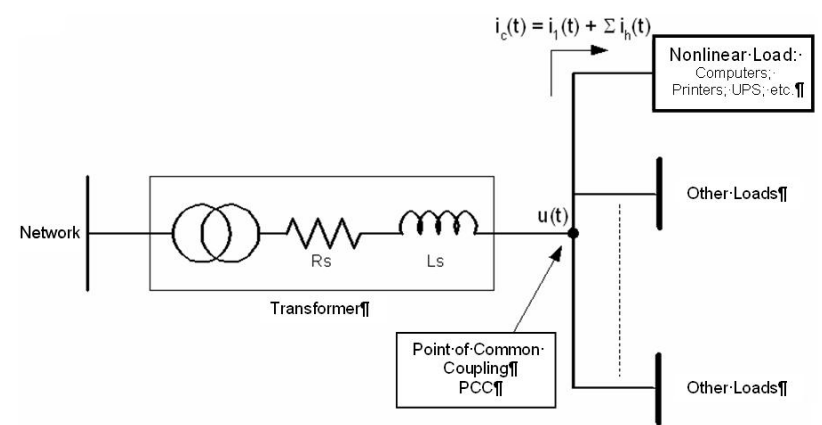

Fig. 1. Electrical installation with nonlinear loads (transformer and others).

\footnotetext{
${ }^{1}$ According to IEC international Standard, used in the European Union, the ratio denominator of the equation (5) is the total rms value. Thus, for the IEC Standard, the THD never exceed $100 \%$.
}

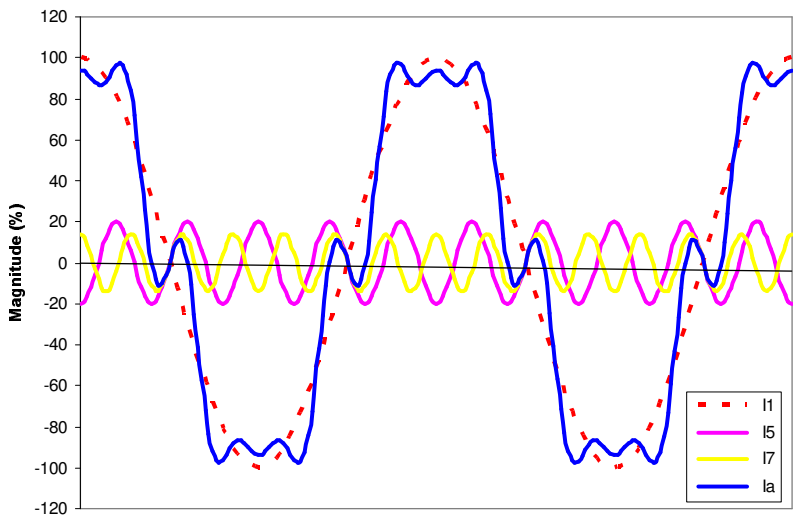

Fig. 2. Representation of $i_{a}(t)$ and Fourier series decomposition (fundamental, $5 .^{\text {th }}$ and $7 .^{\text {th }}$ harmonic currents).

$$
T H D_{X}=\sqrt{\sum_{k=2}^{\infty}\left(\frac{X_{k}}{X_{1}}\right)^{2}}
$$

where for electric signals, $X$ can be a voltage value $(V)$ or a current value $(I)[1],[4],[5]$.

The power factor $(\lambda)$, is defined generically as the reason between the active power and the apparent power absorbed by a load. As it is known, for non-sinusoidal signals, the powers must be calculated with all the harmonics content of the signals (voltage and current), as shown in the expression (6):

$$
\lambda=\frac{P}{S}=\frac{\sum_{k=1}^{\infty} V_{h} I_{h} \cos \left(\theta_{v_{h}}-\theta_{i_{h}}\right)}{\sqrt{\left(V_{1} I_{1}\right)^{2}+\left(V_{1} I_{H}\right)^{2}+\left(V_{H} I_{1}\right)^{2}+\left(V_{H} I_{H}\right)^{2}}}
$$

with:

$$
V_{H}=\sqrt{\sum_{h=1}^{\infty}\left|V_{h}\right|^{2}} \text { and } I_{H}=\sqrt{\sum_{h=1}^{\infty}\left|I_{h}\right|^{2}}
$$

Although it is assumed that, for most cases, the voltage feeding is a sinusoidal signal or with a very low harmonic distortion, it is possible to rewrite $\lambda$ as a function of the power factor due to the phase displacement of the fundamental components $\left(\lambda_{\theta}\right)$ and of the absorbed current $T H D$ :

$$
\lambda=\frac{P}{S}=\frac{\cos \left(\theta_{v_{1}}-\theta_{i_{1}}\right)}{\sqrt{1+T H D_{i}^{2}}}=\frac{\lambda_{\theta}}{\sqrt{1+T H D_{i}^{2}}}
$$

In expressions (6) and (8) it is clearly shown that, due to the relation between $\lambda$ and the THD, the efficiency on the use of the electric energy reduces with the increase of the harmonic level of the voltages and currents.

\section{Correction Options}

There is a set of methods and techniques to attenuate the harmonics amplitude. All present advantages and disadvantages and imply investment in equipment and/or alteration of the feeding system. The search of the best solution must be done in accordance with the total load, 
the installation feeding and the authorized harmonic distortion level. [6]

The attempt to reduce harmonics disturbances suggests the alteration and/or the conception of systems that restrict the dissemination of the harmonics components. Varied solutions are then identified. The most obvious consists on the minimal use of nonlinear loads or on the use of less polluting ones. This has focused the interest in less disturbing equipment conception. The next step is to reduce the impedance of the network through the alteration of the installation or of certain equipments. Finally, it can be chosen solutions based on the placement of filtering equipments for the most harmful currents and/or voltages harmonic components.

\section{A. Structural Alterations}

The structure modifications can be, among other aspects, the feeding system reinforcement (increasing short-circuit power), or the upgrading of the distribution network to improve the PQ indices, from the point of view of the harmonic distortion. But one should bear in mind that the current harmonics spectrums change, according to the load type connected to the buildings distribution networks, and the voltage harmonics resulting of these current harmonics circulation - affect the supplied voltage waveform.

The power short-circuit increase diminishes the voltage $T H D$ at the nonlinear loads interconnection point. This diminution is obtained with the reduction of the total impedance upstream of these same loads. However, any attenuation of the current harmonics level does not exist.

The methods based on the feeding structure alteration are complicated and imply a great investment. The network modification can be based on the resizing of the transformer, which it is one of the equipment with bigger weight in the global investment of the feeding network, or on implementing dedicated feeding sub-networks for polluting loads, with or without filtering devices.

\section{B. Filtering Techniques}

The filtering technique is a harmonic distortion reduction method used in already existing installations, where this distortion has gradually increased, or as a global solution for a new installation. For this method are distinguished basically two techniques: passive filtering and active filtering.

\section{i) Passive Filtering}

The functioning principle of a passive filter is illustrated in Fig. 4. This filter type must be tuned on the harmonic frequency that it intends to attenuate or to eliminate and, typically, is tuned on the 5 th $^{\text {th }}$ order harmonic. This filter type is constituted by a series inductance and a capacitors battery, and the optimum place of its interconnection is next to the harmonics sources (polluting loads) [1,2]. However this filtering technique is not used for new installations.

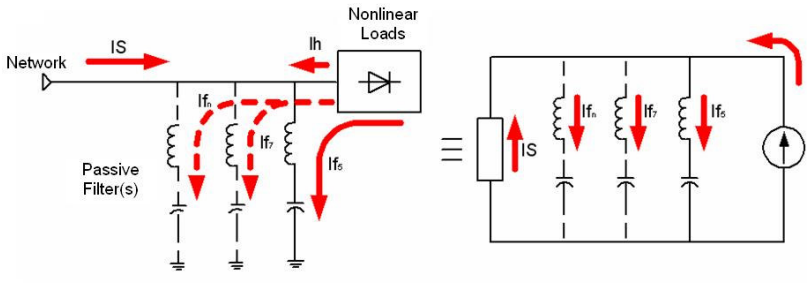

Fig. 4. Passive filter schemes.

It can be used also a set of filters, where each one is tuned to a different harmonic frequency or a band frequency (pass-band filter), as can be seen also in Fig. 4, but, typically, only for filtering the harmonics components of lower orders $(h \leq 25)[1,2]$. The use of several filters allows better harmonics components attenuation.

\section{ii) Active Filtering}

The use of passive filters is a delicate technique, because its performance is sensible to the network impedance variations and/or its fundamental frequency, and new resonance frequencies might appear with amplifying effect of a few harmonics components. With the use of the electronic systems it is possible to control the harmonic distortion in an active form, using active filters. This filters type compensates the harmonic frequencies present in the power electric network, based on the harmonic components introduced in each instant, i.e., function of the load factor, disturbing system type, etc., as illustrated in Fig. 5.a).

The active filters compensate the harmonics frequencies produced by nonlinear loads, introducing new harmonics components of the same order but in opposition of phase, in the electrical circuit, as is presented in Fig. $6[1,6]$. The external active filters are the more adapted solution to the installations with a large number of dynamic loads of small power but, however, they are expensive compared to passive filtering.

The advantages of the active filters to the passive filters are clear, but its power sufficiently remains limited. However, it can be opted to a hybrid compensator, composed by an active filter and passive filters, as illustrated in Fig. 5.b). The hybrid filters allow, relatively to passive filters, a better filtering and eliminate the overload and resonance risk. They can, at the same time, compensate harmonics currents generated by the disturbing load and existing disturbing voltages in the feeding network.

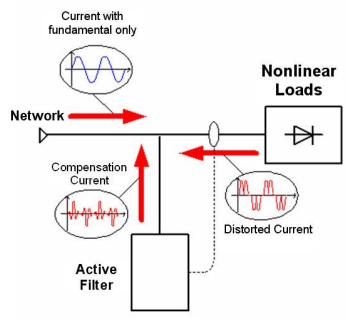

a)

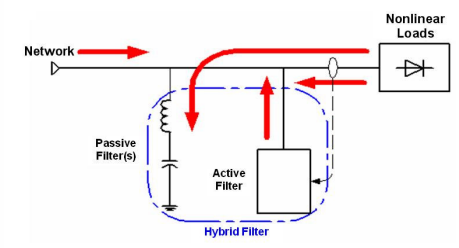

b)
Fig. 5. Scheme of: a) Active filter; b) Hybrid Scheme. 


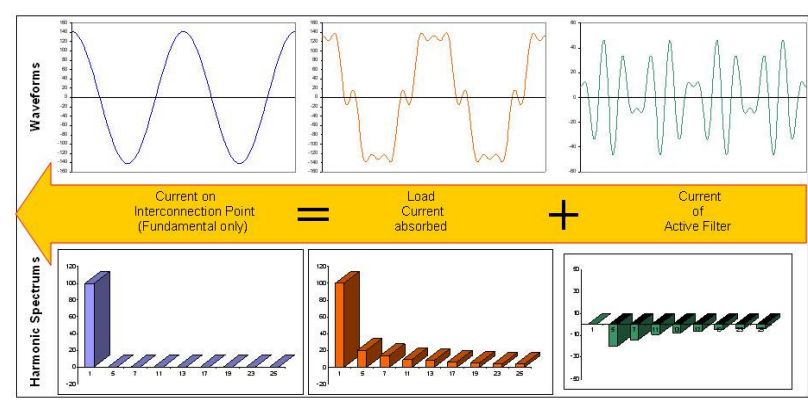

Fig. 6. Current waveforms and harmonic spectrum when active filter is used.

The filtering techniques presented are used in already existing installations where the increase of the harmonic distortion brings problems to the most diverse levels. The active filtering is more flexible than the passive, but presents a very high cost (1.5-2.5) and, even though the large evolution in this field, the commercially available normal rated power still low. Therefore, the use of active filters passes for a dedicated solution to each load and is perfect for dynamic loads. The passive filtering is appropriate for global compensations, being possible to compensate high harmonics currents. However, a passive filter only tunes a frequency or a small frequency band (e.g. 5. ${ }^{\text {th }}, 7^{\text {th }}$ and $11^{\text {th }}$ ), not presenting capacity of adaptation to the load alteration and being able to create resonance with the power factor compensation and, thus, to increase the harmonics frequencies for which it was not tuned. [6]

\section{School Building Audit Results}

For the building audit, study and analysis, it was used a non-invasive acquisition system composed by a commercial power and energy analyzer, voltage and current transducers and a personal computer (PC) for data storage [8]. The measure equipment (Qualistar C.A 8332 by Chauvin Arnoux Group) was designed for verification and maintenance departments in industrial or administrative buildings. This instrument enables the user to obtain the main characteristics of electrical network quality, giving also many calculated values and several processing functions with the most relevant standards.

The school building installation is composed by three floors, 18 classrooms (including labs) and 22 offices. In total, it has 122 personal computers, 18 printers, 4 video projectors, 2 scanners, 20 hub switches, 1 digital copier, 6 HVAC and a lift. The results of the tests are studied according to the most relevant European standard [3-5].

\section{A. Computers and Associated Loads}

The voltage and absorbed current waveforms were monitored for the most important loads present in this facilities building. Fig. 7 shows the voltage and absorbed currents waveforms for the specific electronic loads. This type of load is considered Class D by the IEC 1000-3-2, because it has an input current with "special wave shape" and a fundamental input active power between $75 \mathrm{~W}$ and $600 \mathrm{~W}$. This is the "high crest factor" waveform that corresponds, for example, to the single-phase rectifier input current waveform. [3]
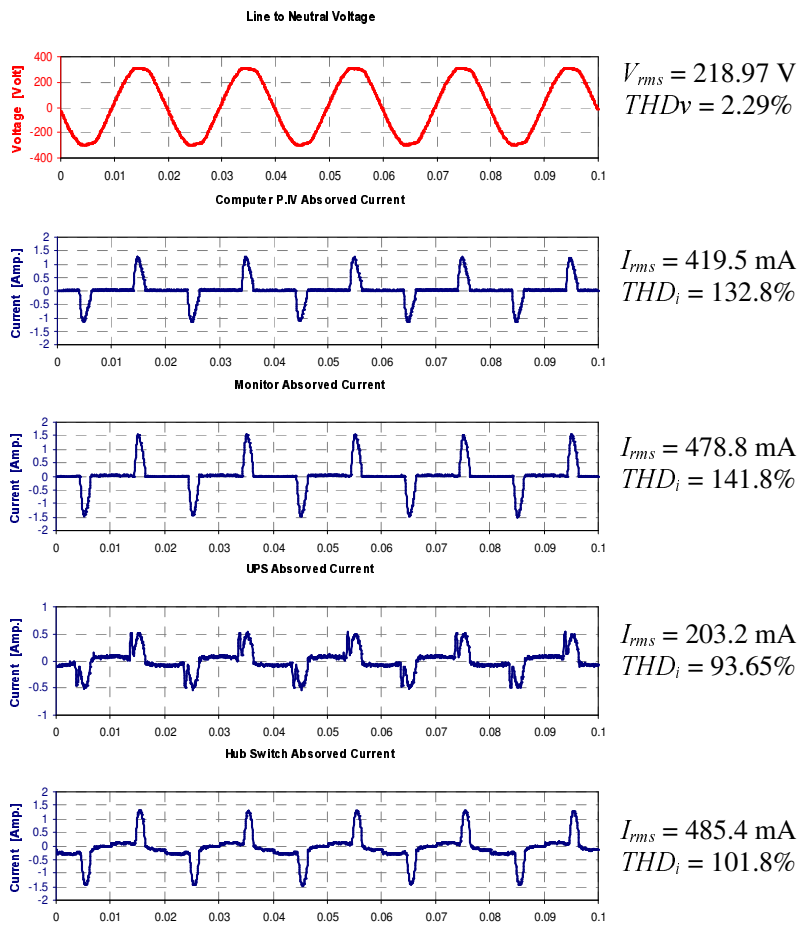

Fig. 7. Voltage and absorbed current waveforms of the computer devices.

For instance, considering the EN 50160 standard, the voltage is within the range of the rms value limits and the $T H D_{v}$ value at distribution line is below the maximum value allowed by this standard, but the $5 .^{\text {th }}$ and $7 .^{\text {th }}$ voltage harmonic orders are above the limits proposed by the most import Standards. For the current, it is registered a high level of the harmonic distortion. The $T H D_{i}$ value of each device is extremely high in percentage of the fundamental, but as the rms value of the absorbed current is much smaller than $16 \mathrm{~A}$, the magnitude of the characteristic harmonics components does not exceed the limits proposed by the IEC 1000-3-2 Standard [3]. TABLE I presents the voltage and absorbed currents $3{ }^{\text {rd }}$ and characteristic (nontriple odd) harmonics amplitudes and $T H D$ for these specific equipments.

For all loads the highest magnitude harmonic current is the $3 .^{\text {rd }}$ order. The $3 .^{\text {rd }}$ harmonic becomes an important issue for grounded-wye systems with current flowing on the neutral and produces two typical problems: overloading the neutral and telephone interference. There

TABLE I. - Harmonic magnitude values of computer devices

\begin{tabular}{cccccc}
\hline \multirow{2}{*}{$\begin{array}{c}\text { Harmonic } \\
\text { Order }\end{array}$} & $\begin{array}{c}\text { L-N } \\
\text { Voltage }\end{array}$ & $\begin{array}{c}\text { Computer } \\
\text { PC }\end{array}$ & Monitor & UPS & $\begin{array}{c}\text { Hub } \\
\text { Switch }\end{array}$ \\
\hline $\mathbf{N .}^{\mathbf{0}}$ & V [\%] & I [\%] & I [\%] & I [\%] & I [\%] \\
\hline 3 & 0.93 & 90.29 & 91.98 & 69.70 & 62.04 \\
5 & 1.82 & 72.63 & 77.48 & 42.42 & 58.32 \\
7 & 1.16 & 50.95 & 58.19 & 18.74 & 31.17 \\
11 & 0.24 & 14.90 & 19.52 & 18.83 & 16.46 \\
13 & 0.50 & 11.79 & 7.99 & 11.88 & 4.73 \\
17 & 0.12 & 10.64 & 10.91 & 15.45 & 5.46 \\
19 & 0.09 & 6.22 & 9.94 & 15.52 & 5.32 \\
23 & 0.05 & 4.09 & 2.26 & 8.29 & 3.64 \\
25 & 0.07 & 5.14 & 1.41 & 9.95 & 3.15 \\
\hline $\boldsymbol{T H D}[\%]$ & 2.29 & 132.8 & 141.8 & 93.65 & 101.8 \\
\hline
\end{tabular}


are also some reports of device malfunction because the line-to-neutral voltage is badly distorted by the triple harmonic voltage resulting from the circulation of the $3 .^{\text {rd }}$ order harmonic currents [1]. The other order harmonics also still sufficiently high, e.g. $7 .^{\text {th }}$ current harmonic has a magnitude that it is about $50 \%$ of the fundamental value for the monitored personal computer.

\section{B. Other Loads}

For the other loads, except lighting, a similar analysis was performed. Fig. 8 shows the voltage and absorbed currents waveforms for the other set of the loads (lift, printer/copier and HVAC). As it was supposed to happen, the voltage distortion value at this distribution network point is identical to the previous point. However, the current waveforms of these loads are not of the same type of the previous analysis. The main difference is that (TABLE II) the $T H D_{i}$ lowered in respect to the value of the computer devices (but continue above the limit value). The $3 .^{\text {rd }}$ harmonic of the currents keeps the highest values (except for the lift). On this case, two of the loads are under $16 \mathrm{~A}$ (Fig. 8), but it is not possible to apply the IEC 100-3-2 standard, because the equipments are not included in one of the proposed class. For these loads, TABLE II also presents the high magnitude of current harmonics for the $250 \mathrm{~Hz}$ and $350 \mathrm{~Hz}$ frequencies. The circulation of these current harmonics through the impedance network increases the voltage distortion presented for the $5 .^{\text {th }}$ and $7 .^{\text {th }}$ voltage harmonics, even if these still below the standards limits. [3]

For the lift, the current harmonic distortion is low because this load is not a typical lift as it does not operate with a three phase induction motor feed by a VFD, where the speed is regulated by PWM technique. It is a hydraulic lift where the principal electric load is an induction motor with constant speed that is necessary to make the pressure into the hydraulic circuit. So, as expected, its absorbed current is less distorted.
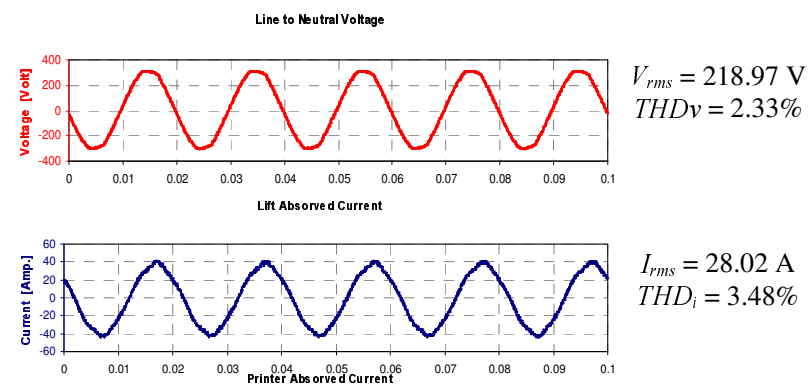

$I_{r m s}=28.02 \mathrm{~A}$ $T H D_{i}=3.48 \%$

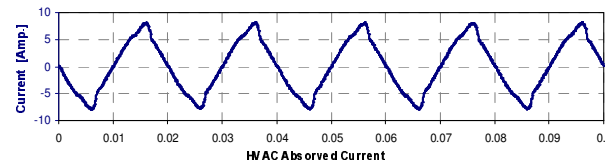

$I_{r m s}=4.8 \mathrm{~A}$ $T H D_{i}=12.45 \%$

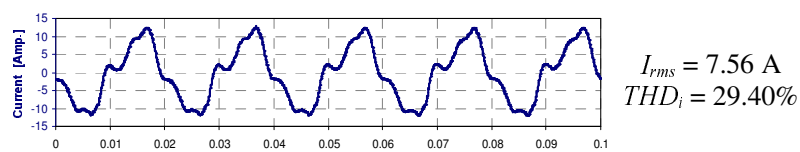

Fig. 8. Voltage and absorbed currents waveforms of the other loads.
Fig. 9 presents one typical facility day (02/10/2006). There are two periods where the total load level comes across the highest value, between $11 \mathrm{~h} 30$ and $13 \mathrm{~h} 30$ and at $17 \mathrm{~h}$. In these two periods, the value of the $T H D_{i}$ reaches its lower value. Therefore the $T H D_{i}$ varies inversely with the load level increase, as already exposed in [7], but the $T H D_{v}$ progresses to the highest values on these periods. On the other hand, the day periods where the $T H D_{i}$ takes the higher value do not correspond only to the periods of lesser load factor: there are situations where the $T H D_{i}$ takes maximum values for half of the daily maximum load. It should also be pointed out that the $T H D_{i}$ never assumes lesser values than $15 \%$, as in the period where the absorbed current correspond the maximum current, and also present a maximum value, $90 \%$, at $10 \mathrm{~h} 30 \mathrm{~m}$, when the total load is $50 \%$ of the maximum value (see Fig. 9).

As it is verified in Fig. 10, only the harmonics of major order $\left(>13^{\text {th }}\right)$ take values below of $10 \%$ of the fundamental component, during all day. On the other hand, the harmonics of lower frequencies $\left(<7 .{ }^{\text {th }}\right)$ are always above of $10 \%$ of the fundamental one. From this figure, it can be seen that in the periods where the $T H D_{i}$ takes the highest and lower values this trend is followed, as expected, by the lower frequencies magnitudes. They are the ones that have greater weight in the $T H D_{i}$.

\section{Proposed Corrective Measures}

For this audit, were also registered high global values of the current harmonic distortion. Even if each equipment does not exceed boundary-values of the IEC 1000-3-2 Standard, globally the presented percentages values are not compatible with any Standard. [4]

TABLE II. - Harmonic magnitude values of other loads

\begin{tabular}{ccccc}
\hline \multirow{2}{*}{$\begin{array}{c}\text { Harmonic } \\
\text { Order }\end{array}$} & $\begin{array}{c}\text { L-N } \\
\text { Voltage }\end{array}$ & Lift & Printer/Copier & HVAC \\
\hline N. $^{{ }^{*}}$ & V [\%] & I [\%] & I [\%] & I [\%] \\
3 & 0.519 & 0.526 & 9.39 & 22.52 \\
5 & 1.818 & 3.151 & 6.49 & 15.25 \\
7 & 1.071 & 0.845 & 3.82 & 1.86 \\
11 & 0.300 & 0.268 & 1.93 & 1.90 \\
13 & 0.485 & 0.198 & 1.37 & 0.92 \\
17 & 0.212 & 0.095 & 1.52 & 0.71 \\
19 & 0.104 & 0.176 & 0.75 & 0.46 \\
23 & 0.017 & 0.186 & 0.43 & 0.53 \\
25 & 0.096 & 0.099 & 0.35 & 0.22 \\
\hline THD [\%] & 2.33 & 3.48 & 12.45 & 29.40 \\
\hline
\end{tabular}

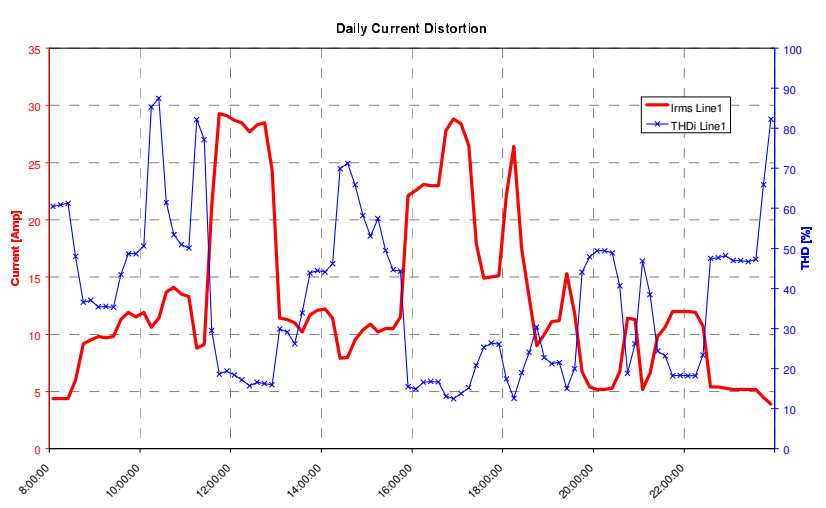

Fig. 9. Daily current waveform and harmonic distortion. 


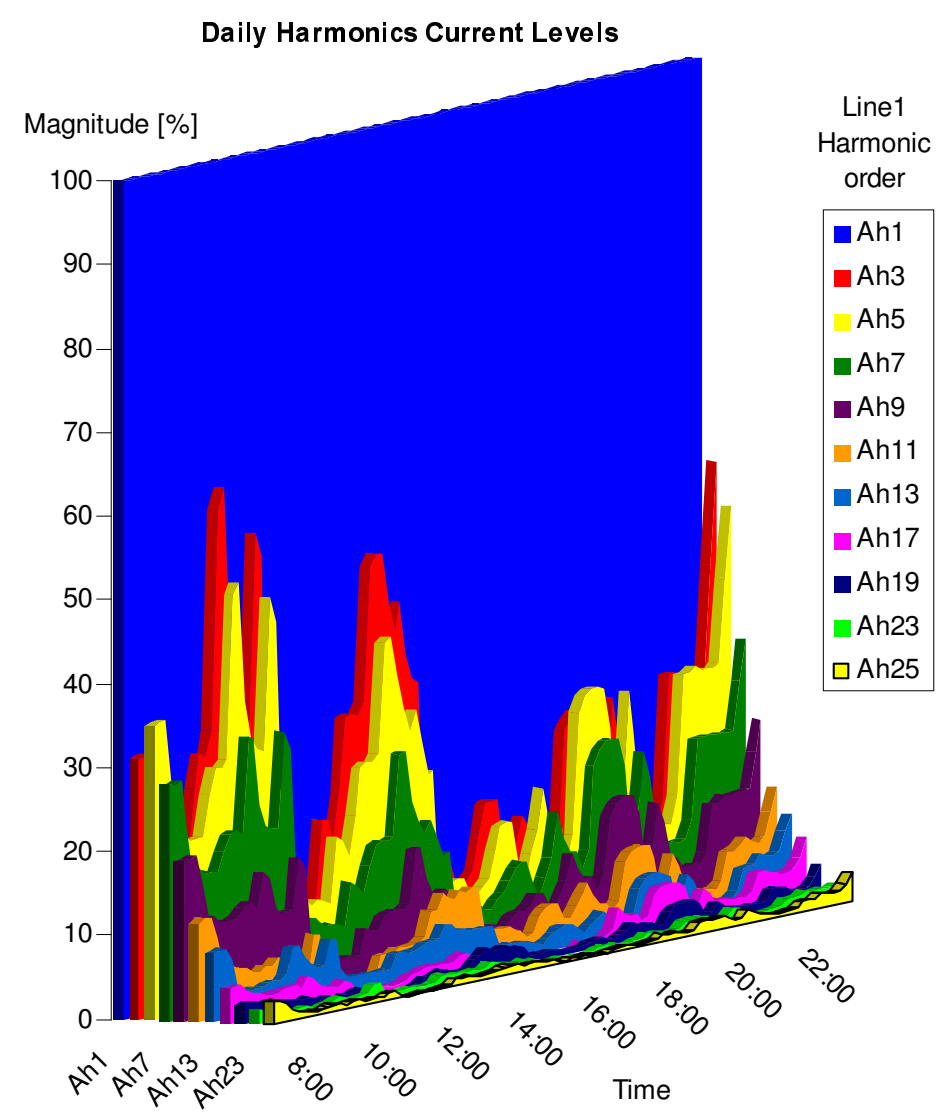

Fig. 10. Daily Harmonics current levels evolution.

Thus, some problems have been verified next to the circuit-breakers of the cabinets with unexpected opening and abnormal heating. Therefore, it is necessary to propose and implement some measures necessary for the PQ improvement of this installation. Some conclusions can also be extracted for accomplishment on future new electric installations projects for facilities buildings.

In the present case, it is not possible to reduce directly the emissions of harmonics currents generated by the informatics equipment; therefore, it is needed to reduce the currents harmonics, specially the lower order harmonics $\left(3 .^{\text {rd }}, 5 .^{\text {th }}\right.$ and $\left.7 .^{\text {th }}\right)$, in the feeding network.

As this installation was implemented long time ago, there is no viability to use dedicated feeding circuits to the informatics loads, which would allow using only one compensation filter.

Harmonic line current reduction can be achieved by using different techniques. The most common used techniques for harmonic current reduction are line filters, using passive components, and active electronic circuitry.

Harmonic line current reduction using passive components (inductors and capacitors) introduces a high impedance for the harmonics thus smoothing the input current to an electronic equipment. Effectively, the appraised solution is the installation of filters, one for each cabinet and each phase. It is extremely delicate to implement tuned passive filters on the lower order frequencies $(150 \mathrm{~Hz}, 250 \mathrm{~Hz}$ and $350 \mathrm{~Hz})$, without severely modifying the network impedance for the $50 \mathrm{~Hz}$ frequency. In fact, this filter type is capacitive for the fundamental network frequency, which is not compatible with some loads (PWM inverters, as used in some lift, for instance).

Harmonic line current reduction using active electronic circuitry shapes the input current of electronic equipment proportionally to the applied line voltage, thus giving a sinusoidal input current in phase with the line voltage. Therefore, the best solution is the use of an active filter (Fig. 5) between informatics equipment and cabinets. The active filters must be placed as close as possible to the loads to always prevent the harmonics currents circulation in the conductors between loads and the position of filters interconnection, avoiding a reinforcement of the installation in this zone. On the other hand, being the informatics loads of low power (about $400 \mathrm{~W}$ each computer), this solution is affordable because the capacity of active filters compensation still sufficiently limited in terms of high power and the cost is directly proportional to the power of the active filter.

\section{Conclusions}

In the work presented in this communication, it is performed a complete analysis of the electrical installation allowing the knowledge of the supply quality 
in the considered facility building. It is used the weekly and daily data supply waveforms and PQ indexes, acquired by recent power analyser, allowing to study the voltage and current waveform distortion of this specific building, where the main load are computer devices. The data of the voltage and current waveforms is then used to study and analyse the best solution to mitigate the principal PQ problems. For this, a set of methods and techniques to attenuate the harmonics amplitude, at the computer devices and in the installation, is presented and discussed. Each one of them presents advantages and disadvantages and implies investment in equipment and/or modification of the power supply system. The search of the best solution must be a function of the total load, of the installation feeding and of the level of authorized harmonics distortion by the international standards.

This work intends to alert the technicians interested in Power Quality issues, as well as those unaware of it, by embracing a large number of aspects related with the subject. This analysis can provide some help in the future dimensioning and project of the electrical installation in the facility buildings, from the point of view of the harmonic distortion and the best localization of the problematic loads, i.e. in dedicated feeding circuits.

\section{References}

[1] Dugan, R., McGranaghan, M., Wayne, H., 1999 , Electrical Power Systems Quality, McGraw-HiLl, New YORK, USA.

[2] Bose, K., Power Electronics and Variable Frequency Drives, Technology and Applications; New York: USA, IEEE Press cop., 1997.

[3] UIE, Types of Disturbances and Relevant Standards, Guide to Quality of Electrical Supply for Industrial Installations, "Power Quality" Working Group WG2.

[4] IEEE STD 519-1992, IEEE Recommended Practices and Requirements for Harmonic Control in Electric Power Systems, IEEE Industry Applications Society/Power Engineering Society.

[5] IEEE PES HARMONIC WorkING GRoup, Characteristics and Modelling of Harmonic Sources-Power Electronic Devices, IEEE Transactions on Power Delivery, vol. 16, n. ${ }^{\circ}$, pp. 791-800, October 2001.

[6] Trovão, J. P., Harmonic Distortion Monitoring and Analysis Integrated System - a Systematic Approach for the Industrial Sector- (in Portuguese), M.Sc Thesis, Faculty of Science and Technology of the University of Coimbra, Portugal, 2004;

[7] Trovão, J., Jorge, H., Analysis of Harmonic Current Propagation in Industrial Sector in Function of the Load Level, Proceedings of the International conference on Renewable Energy and Power Quality, 6 pp., CD-ROM, Vigo, Spain, April 9-11, 2003.

[8] Davis, E., Emanuel, A., Pileggi, D., Harmonic Pollution Metering: Theoretical Considerations, IEEE Transactions on Power Delivery, vol. 15, n. ${ }^{\circ}$ 1, pp. 19-23, January 2000. 